\title{
Application of Topsis Reverse Logistics Operating Method
}

\author{
Amit Kumar ${ }^{1}$ \\ ${ }^{1}$ Assistant Professor, Institute of Business Management, GLA University, Mathura, India. \\ E-mail: amit.kumar@gla.ac.in
}

Article History: Received: 11 January 2021; Accepted: 27 February 2021; Published online: 5 April 2021

\begin{abstract}
Coordination's re-appropriation is becoming increasingly necessary because more and more organizations worldwide are unable to deal with their troubling versatile chains, re-appropriate exercises in coordination with the outsider coordinators (3PL) or professional co-operatives in coordination. Through redistributing teamwork exercises, businesses will focus on their business tasks at the core while at the same time achieving economic productivity and enhancing transport delivery and customer loyalty. Transport structure and the board of directors are of fundamental benefit to 3PLs. You can transport your own armada or haggle with at least one external carriers. In addition, 3PLs have traffic light inbound and outbound. To boost the courses, transport uses various transport methods and administration of installations. Switch coordination is one form of coordination that has an important impact on the board through ecological implementation and growing client awareness. The purpose of this paper is to enable heads of organization to determine most appropriate invert collaboration modes of operating with the complex models. There are three basic work method of coordinating for big corporations: self-supporting, joint endeavor and redistribute. To rank the other options, we applied TOPSIS as a dynamic apparatus. At long last, a model has been delineated to feature procedural execution of proposed model.
\end{abstract}

Keywords: TOPSIS, Reverse Logistics Operating Modes, 3PLP.

\section{Introduction}

Increased serious weights and worries regarding stock costs enable businesses to determine which activities should be carried out in-house and redistributed in order to maximize production and benefit for investor estimation. Corporate exercises have been chosen to redistribute, e.g. finance, bookkeeping, customer service and coordination [1-4]. The contracting of teamwork capabilities to an external contractor is a reference to (3PL). The introduction of a 3PL supplier and customer relationship is controlled periodically using hierarchical and relationship steps. The Indian 3PL market has grown least and is deeply divided. Whatever, 3PL's growth potential in India is immense, around 20\% per year, and if organized costs can be reduced from the current $13 \%$ of GDP to $8.7 \%$ (at the level of the US), investment funds will amount to some $\$ 20$ billion, which could result in a possible $4.3 \%$ reduction in Indian commodity costs in a global manner [5-10]. Respondents found the most significant obstacles, to development of 3PLs and the most significant open door to 3PL development was seen in India Transportation and Interchange system. as the expanding consciousness of Indian firms towards advantages of co-ordinations redistributing [11-15].

Inversion coordination, as the large majority of companies use it as a critical method to satisfy their consumers, has a lot to do late and can generate big incomes. Invert coordination for warehousing and distribution is an important feature of a productive sector. Coordination involves packing and delivering end goods from end customer to manufacturer [16-18]. Recognizing that versatile chain networks can be linked both forward and switch, and this will save business a lot of money. For corporations, the management of the return stream usually needs a clear basis with unique data structures for the management of income [19-21]. The key justification for this document is for an outside coordination provider (3PLP) to select the best approaches to engage in retroactive coordination tasks [27-30].

\section{Literature Review}

"Meade and Sarkis" (2002) built up model for choosing and assessing outsider converse co-ordinations supplier (3PRLP) utilizing Analytic Network Process (ANP). Notwithstanding, their model didn't speak to a device for deciding if to re-appropriate opposite co-ordinations exercises, yet it helped in choice of choosing 3PRLP once redistributing methodology was picked by firm [22-24, 31].

"Ravi et al." (2005a) introduced ANP depended choice model to structure issue of direct converse coordinations for End-of-life PCs in a various leveled structure. "Ravi et al." (2005b) utilized interpretive Structural Modeling (ISM) based way to deal with model converse co-ordinations factors regularly found in PC equipment gracefully chains. Ravi and Shankar (2005) dissected the collaboration among the significant obstructions, which block or forestall the utilization of opposite co-ordinations in car ventures. They used the ISM strategy to comprehend the common impacts among the hindrances[37]. Bian and Yu (2006) broke down different nations in the Asia pacific locale to decide their reasonableness in completing opposite co-ordinations tasks for a worldwide electrical producer utilizing expository chain of importance measure (AHP). "Staikos and 
Rahimifard" (2007) applied AHP as dynamic model to distinguish most proper reuse, recuperation and reusing choice for post-purchaser shoes. "Araz et al." (2007) proposed procedure for redistributing the board using data got from re-appropriating determination measure. The proposed system depended on PROMETHEE (Preference Ranking Organization method for enrichment evaluations) and fluffy objective programming. Correspondingly, Efendigil et al. (2008) proposed strategy for choosing fitting and attractive outsider sellers considering the abstract necessities of the organization. From the survey of writing it is proposed to settle on a choice for 3PLP on the determination of opposite co-ordinations working modes [25, 26, 32-35].

\section{Illustrations of Problem}

Inverting exercises for teamwork can improve efforts, benefit customers and reduce costs of creation. The external collaboration (3PL) providers will maximize the benefits of their clients and minimize costs by allowing businesses to concentrate on their center capacities. As a leading coordinating service or 4PL provider, a 3PL provider is partnered with a broad community of 3PL suppliers. A 3PLP that gives an organization's forward coordination has also begun to give the administration of the opposite coordination. To offer this extra assistance the 3PLP can have three kinds of working modes: self-uphold (SS), joint endeavor (JV) and redistributing (OS). The models and the sub-rules, which are generally predominant and significant in the choice of converse coordinations working modes distinguished by the chief, are given in Table 1.

\section{Topsis Methodologies}

TOPSIS is used for the option of reverse logistics operating modes as a method for decision-making multicriteria community. The assessment process measures the critical weights of different AHP parameters. TOPSIS classification method is carried out for the remaining evaluations following determination of criteria weight.

Table 1. Criteria and Sub-Criteria for Choosing Reverse Logistics Operating Modes

\begin{tabular}{ll}
\hline \multicolumn{1}{c}{ "Criteria } & \multicolumn{1}{c}{ Sub-criteria } \\
\hline financial factors (A) & Cost (AT) \\
& Profit (A2) \\
Management factors (B) & Management (BI) \\
& Staff (B2), \\
Strategy factors (C) & Invest (CI)" \\
& \\
\hline
\end{tabular}

Hwang and Yoon (1981) suggested TOPSIS first, considering that the chosen alternative should be found closest to the positive ideal arrangement (PIS) and the distance from the negative ideal arrangement (NIS) in order the settlement of different dynamic standards. At the point that the company wanted to conduct turn collaboration practices, it found an approach that could be used in the choice of conversational modes of coordination. The ideal choice is therefore based on a relative similarity to the ideal arrangement and is therefore kept away from the situation in which ideal and negative ideal arrangements have the same closeness. The figuring measures utilized in this strategy are introduced beneath:

(i) Establish decision matrix for alternative performance

\begin{tabular}{lllll}
\hline & $\mathbf{f}_{1}$ & $\mathbf{f}_{2}$ & $\ldots \ldots$ & $\mathbf{f}_{\mathbf{j}}$ \\
\hline $\mathrm{A}_{1}$ & $\mathrm{X}_{11}$ & $\mathrm{X}_{12}$ & $\ldots \ldots$ & $\mathrm{X}_{1 \mathrm{j}}$ \\
$\mathrm{A}_{2}$ & $\mathrm{X}_{21}$ & $\mathrm{X}_{22}$ & $\ldots \ldots$ & $\mathrm{X}_{2 \mathrm{j}}$ \\
$\cdot$ & $\cdot$ & $\cdot$ & $\ldots \ldots$ & $\cdot$ \\
$\cdot$ & $\cdot$ & $\cdot$ & $\ldots \ldots$ & $\cdot$ \\
$\cdot$ & $\cdot$ & $\cdot$ & $\ldots \ldots$ & $\cdot$ \\
$\mathrm{A}_{\mathrm{k}}$ & $\mathrm{X}_{\mathrm{k} 1}$ & $\mathrm{X}_{\mathrm{k} 2}$ & $\ldots \ldots$ & $\mathrm{X}_{\mathrm{kj}}$ \\
\hline
\end{tabular}

"Where $\mathrm{x}_{\mathrm{kj}}$ denotes the performance of criteria $\mathrm{f}_{\mathrm{j}}$ for alternative $\mathrm{A}_{\mathrm{k}}$, given $\mathrm{k}=1,2 \ldots \mathrm{s}$;

$\mathrm{j}=1,2 \ldots \mathrm{m}$.

(ii) Normalize the $D$ matrix $R=r_{k j}$. The normalized $r_{k j}$ is calculated as,

$$
\mathrm{r}_{\mathrm{kj}}=\frac{x_{k j}}{\sqrt{\sum_{j=1}^{m} x_{k j}^{2}}}, \mathrm{k}=1,2 \ldots \ldots . \mathrm{s} ; \mathrm{j}=1,2 \ldots \ldots \ldots . . \mathrm{m} .
$$

(iii) Create the weighted normalized performance matrix.

TOPSIS defines the weighted normalized performance matrix as, 


$$
\mathrm{V}_{\mathrm{kj}}=\mathrm{w}_{\mathrm{j}} \mathrm{Xr}_{\mathrm{kj}} \quad \mathrm{V}=\left(\mathrm{V}_{\mathrm{kj}}\right), \forall \mathrm{k}, \mathrm{j}
$$

Where $\mathrm{w}_{\mathrm{j}}$ denotes the weight of criterionj as calculated by AHP

(iv) Identify the positive ideal solutions $\left(\mathrm{V}^{*}\right)$ and negative ideal solutions $\left(\mathrm{V}^{-}\right)$.

$$
\begin{aligned}
& \mathrm{V}^{*}=\left\{\mathrm{V}^{*}{ }_{1}, \mathrm{~V}^{*}{ }_{2} \ldots \ldots \ldots \ldots . . . . . . \mathrm{V}^{*}{ }_{\mathrm{m}}\right\}=\left\{\left({ }_{k}^{\max } \mathrm{v}_{\mathrm{kj}}|\mathrm{j} \in \mathrm{J}|\right)\left({ }_{k}^{\min } \mathrm{V}_{\mathrm{kj}}|\mathrm{j} \in \mathrm{J}|\right)\right\} \\
& \mathrm{V}^{-}=\left\{\mathrm{V}_{1}^{-}, \mathrm{V}_{2}^{-} \ldots \ldots \ldots \ldots \ldots \mathrm{V}_{\mathrm{m}}^{-}\right\}=\left\{\left({ }_{k}^{\min } \mathrm{V}_{\mathrm{kj}} \mathrm{j} \in \mathrm{J} \mid\right)\left({ }_{k}^{\max } \mathrm{V}_{\mathrm{kj}}|\mathrm{j} \in \mathrm{J}|\right)\right\} ”
\end{aligned}
$$

(v) Calculate Euclidean distance between positive ideal solution $\left(\mathrm{S}_{\mathrm{k}}\right)$ and negative ideal solution $\left(\mathrm{S}_{\mathrm{k}}^{-}\right)$for each alternative.

$$
\begin{aligned}
& \text { “S } *_{\mathrm{k}}=\sqrt{\sum_{j=1}^{m}\left(v_{k j}-v_{j}^{*}\right)^{2}} \mathrm{k}=1,2 \ldots \mathrm{s} ; \mathrm{j}=1,2 \ldots \mathrm{m} \\
& \mathrm{S}_{\mathrm{k}}^{-}=\sqrt{\sum_{j=1}^{m}\left(v_{k j}-v_{j}^{-}\right)^{2}} \mathrm{k}=1,2 \ldots \mathrm{s} ; \mathrm{j}=1,2 \ldots \mathrm{m} "
\end{aligned}
$$

(vi) Calculate the relative closeness to theideal solution of each alternative

$$
\text { " } C_{K}^{*}=\frac{s_{K}^{-}}{S_{k}^{*}+S_{k}^{-}}, \mathrm{k}=1,2 \ldots . . \mathrm{s} "
$$

Where $0 \leq C_{k}^{*} \leq 1$; that is, an alternative $\mathrm{A}_{\mathrm{k}}$ is closer to $\mathrm{V}^{*}$ as $C_{k}^{*}$ approaches 1

(vii) Rank preference order by.

A set of alternatives can be preference ranked in descending order of. Larger index values indicate better performance of alternatives.

\section{Case Description}

In this area model is presented to outline how the master determination system proposed is used to choose ideal modes of working opposite coordination for a 3PLP now interested in potential coordination. Currently, the competing co-ordination practices are carried out by three working methods: self-help, collective initiative and re-appropriation. The decision matrix (Table 2) is formed as explained in step 1 for sub-criteria Vs alternative.

Table 2. Decision Matrix for Alternative Performance

\begin{tabular}{llllll}
\hline & A1 & A2 & B1 & B2 & C1 \\
\hline SS & 0.06560 & 0.63450 & 0.08250 & 0.08260 & 0.63470 \\
OS & 0.78620 & 0.10630 & 0.57530 & 0.57450 & 0.10650 \\
JV & 0.14970 & 0.26540 & 0.34350 & 0.34350 & 0.26700 \\
\hline
\end{tabular}

The Normalized performance matrix (Table3) is calculated by using equation (1).

Table 3. Normalized Performance Matrix

\begin{tabular}{lccccc}
\hline & A1 & A2 & B1 & B2 & C1 \\
\hline SS & 0.08332 & 0.91535 & 0.12187 & 0.12167 & 0.91335 \\
OS & 0.97412 & 0.15387 & 0.85254 & 0.85344 & 0.15357 \\
JV & 0.18685 & 0.37697 & 0.50750 & 0.50250 & 0.37497 \\
\hline
\end{tabular}

The weighted normalized performance matrix (Table 4) is calculated by using equation (2).

Table 4. Weighted Normalized Performance Matrix

\begin{tabular}{lclccc}
\hline & A1 & \multicolumn{1}{c}{ A2 } & B1 & B2 & C1 \\
\hline SS & 0.03918 & 0.14538 & 0.02638 & 0.00523 & 0.09692 \\
OS & 0.46606 & 0.021 & 0.18498 & 0.03665 & 0.01620 \\
JV & 0.08846 & 0.05962 & 0.11034 & 0.02187 & 0.03975 \\
\hline
\end{tabular}

The positive and negative ideal solutions (Table 5) are calculated by using equations (3) \& (4).

Table 5. Positive Ideal Solutions $\left(\mathrm{V}^{*}\right)$ and Negative Ideal Solutions $\left(\mathrm{V}^{-}\right)$

\begin{tabular}{llllll}
\hline$\left(\mathrm{V}^{*}\right)$ & 0.46600 & 0.14638 & 0.18458 & 0.03655 & 0.09642 \\
\hline$\left(\mathrm{V}^{-}\right)$ & 0.03928 & 0.02531 & 0.02658 & 0.00543 & 0.01630 \\
\hline
\end{tabular}

The Euclidean distance between positive ideal solution and negative ideal solution for each alternative (Table $6)$ is calculated by using equations (5) \& (6). 
Table 6. Euclidean Distance between $\left(S_{k}^{*}\right)$ and $\left(S_{k}^{-}\right)$for each Alternative

\begin{tabular}{llll}
\hline & SS & OS & JV \\
\hline$\left(S_{k}^{*}\right)$ & 0.456472 & 0.145513 & 0.398742 \\
$\left(S_{k}^{-}\right)$ & 0.145513 & 0.456472 & 0.107501 \\
\hline
\end{tabular}

The relative closeness to ideal solution of each alternative (Table 7) is calculated by using equation (7).

Table 7. Relative Closeness $\left(C_{k}^{*}\right)$ to The Ideal Solution of each Alternative

\begin{tabular}{llll}
\hline & SS & OS & JV \\
\hline$\left(C_{k}^{*}\right)$ & 0.24172 & 0.75828 & 0.21235 \\
Rank & 2 & 1 & 3 \\
\hline
\end{tabular}

\section{Conclusion}

Extending center skill and the difficulty of teamwork operations has prompted several organizations, including transportation and stock management, to re-appropriate organized exercises to third-party logistics providers (3PL). Moreover, companies refuse to securing capital storage plants, lorries, divisions etc, by reappropriating 3PLs. Globalization is also a factor that influences the appropriation of 3PL administrations. As companies expand through public limits, the need for complex administrations such as multi-modular vehicles and foreign trade laws increases. The study of this paper aims to include AHP and TOPSIS approaches in the determined period of working modes for 3PLP in opposite coordination. The TOPSIS approach for the case study offers the highest need for redistribution with a proximity coefficient of 0.75828 . With a close-up coefficient of 0.21235 , the elective joint attempt works least. Second, endorse the second optional positions with a 0.24172 proximity coefficient. Re-appropriation may therefore be preferred as the optimal tool for practicing reverse coordination.

\section{References}

7. Araz, C., Ozfirat, P.M., \& Ozkarahan, I. (2007). An integrated multi-criteria decision-making methodology for outsourcing management. Computers \& Operations Research, 34(12), 3738-3756.

8. Bian, W., \& Yu, M. (2006). Location analysis of reverse logistics operations for an international electrical manufacturer in Asia Pacific region using the analytic hierarchy process. International Journal of Services operations and informatics, 1(1/2), 187-201.

9. Efendigil, T., Onut, S., \& Kongar, E. (2008). A holistic approach for selecting a third-party reverse logistics provider in the presence of vagueness. Computers \& Industrial Engineering, 54(2), 269-287.

10. Kumar, K., Sharma, K., Verma, S., \& Upadhyay, N. (2019). Experimental Investigation of GrapheneParaffin Wax Nanocomposites for Thermal Energy Storage. Materials Today: Proceedings, 18, 51585163.

11. Goyal, M. (2018). Shape, size and phonon scattering effect on the thermal conductivity of nanostructures. Pramana, 91(6), 87.

12. Goyal, M., \& Gupta, B.R.K. (2019). Study of shape, size and temperature-dependent elastic properties of nanomaterials. Modern Physics Letters B, 33(26), 1950310.

13. Goyal, M., \& Gupta, B.R.K. (2019). Analysis of shape, size and structure dependent thermodynamic properties of nanowires. High Temperatures--High Pressures, 48(5/6), 481-495.

14. Hwang, C., \& Yoon, K. (1981). Multiple attribute decision making: Methods and application. New York: Springer Publications.

15. Meade, L., \& Sarkis, J. (2002). A conceptual model for selecting and evaluating third-party reverse logistics providers. Supply Chain Management: An International Journal, 7(5), 283-295.

16. Singh, P.K., \& Sharma, K. (2018). Mechanical and Viscoelastic Properties of In-situ Amine Functionalized Multiple Layer Grpahene/epoxy Nanocomposites. Current Nanoscience, 14(3), 252-262.

17. Singh, P.K., \& Sharma, K. (2018). Molecular Dynamics Simulation of Glass Transition Behaviour of Polymer based Nanocomposites. Journal of Scientific \& Industrial Research, 77(10), 592-595.

18. Kumar, A., Sharma, K., \& Dixit, A.R. (2020). Carbon nanotube-and graphene-reinforced multiphase polymeric composites: review on their properties and applications. Journal of Materials Science, 1-43.

19. Shukla, M.K., \& Sharma, K. (2019). Effect of carbon nanofillers on the mechanical and interfacial properties of epoxy based nanocomposites: A review. Polymer Science, Series A, 61(4), 439-460.

20. Kumar, A., Sharma, K., \& Dixit, A.R. (2020). A review on the mechanical and thermal properties of graphene and graphene-based polymer nanocomposites: understanding of modelling and MD simulation. Molecular Simulation, 46(2), 136-154.

21. Mausam, K., Sharma, K., Bharadwaj, G., \& Singh, R.P. (2019). Multi-objective optimization design of die-sinking electric discharge machine (EDM) machining parameter for CNT-reinforced carbon fibre 
nanocomposite using grey relational analysis. Journal of the Brazilian Society of Mechanical Sciences and Engineering, 41(8), 348.

22. Ravi, V., Shankar, R., \& Tiwari, M.K. (2005a). Analyzing alternatives in reverse logistics for end-oflife computers: ANP and balancedscorecard approach. Computers \& Industrial Engineering, 48(2), 327 356.

23. Ravi, V., Shankar, R., \& Tiwari, M.K. (2005b). Productivity improvement of a computer hardware supply chain. International Journal of Productivity and Performance Management, 54(4), 239-255.

24. Ravi, V., \& Shankar, R. (2005). Analysis of interactions among the barriers of reverse logistics. Technological Forecasting and Social Change, 72(8), 1011-1029.

25. Staikos, T., \& Rahimifard, S. (2007). A decision-making model for waste management in the footwear industry. International Journal of Production Research, 45(18-19), 4403-4422.

26. Kumar, A., Sharma, K., \& Dixit, A.R. (2019). A review of the mechanical and thermal properties of graphene and its hybrid polymer nanocomposites for structural applications. Journal of materials science, 54(8), 5992-6026.

27. Sharma, K., \& Shukla, M. (2014). Three-phase carbon fiber amine functionalized carbon nanotubes epoxy composite: processing, characterisation, and multiscale modeling. Journal of Nanomaterials, 2014.

28. Sharma, K., Kaushalyayan, K.S., \& Shukla, M. (2015). Pull-out simulations of interfacial properties of amine functionalized multi-walled carbon nanotube epoxy composites. Computational Materials Science, 99, 232-241.

29. Yadav, A., Kumar, A., Singh, P.K., \& Sharma, K. (2018). Glass transition temperature of functionalized graphene epoxy composites using molecular dynamics simulation. Integrated Ferroelectrics, 186(1), 106-114.

30. Singh, P.K., Sharma, K., Kumar, A., \& Shukla, M. Effects of functionalization on the mechanical properties of multiwalled carbon nanotubes: A molecular dynamics approach. Journal of Composite Materials 51(5), 671-680.

31. Kim, J. (2019). The Mediating Effect of Fear of Missing Out between Interpersonal Relationship Orientation and SNS Addiction Tendency in College Students. Asia-pacific Journal of Convergent Research Interchange, 5(3), 1-9.

32. Xiaohui, L. (2019). The Comparative Study on Management of School-based Curriculum in South Korea and China. Asia-pacific Journal of Convergent Research Interchange, 5(3), 11-20.

33. Kim, K. (2019). T Happy People Does Not Compare: Difference in Social Comparison between Happy and Unhappy People. Asia-pacific Journal of Convergent Research Interchange, 5(3), 21-30.

34. Lee, J. (2019). The Crisis Facing Terrestrial Broadcasters and Reorganization Policy of Television Industry. Asia-pacific Journal of Convergent Research, 5(3), 31-40,

35. Jung, H.W., Park, S.G., \& Cho, J.R. (2019). A Study on the Literacy of Multicultural Family Children with Underachievement and Cognitive-Linguistic Variables Using the Korean Test of Literacy Diagnosis. Asia-pacific Journal of Convergent Research, 5(3), 41-51.

36. Dhamija, A. (2020). The changing paradigms and evolving dynamics of faith-based tourism in India. International Journal of Scientific and Technology Research, 9(2), 2347-2352.

37. Dhamija, A. (2019). Surviving the COVID-19 menace: A case of higher education sector. International Journal of Psychosocial Rehabilitation, 9(4), 77-86.

38. Dhamija, A. (2019). Adolescent attachment towards passion, intimacy and commitment for spirituality establishment. International Journal of Management and Business Research, 9(4), 77-86.

39. Khan, W., Jamshed, M., Fatima, S., \& Dhamija, A. (2019). Determinants of Income Diversification of Farm Households' in Uttar Pradesh, India. Forum for Social Economics, Routledge, 1-19.

40. Dhamija, A. (2019). Relevance of vedic management in contemporary times. International Journal of Recent Technology and Engineering, 8(2), 3918-3921.

41. Khan, S.A., Ahmad, S., \& Jamshed, M. (2020). IoT-enabled services in online food retailing. Journal of Public Affairs, e2150. 